\title{
The Impact of Virtual Currencies on Money, Banking and Economic Market: An Analysis and Overview of Modern Economics
}

\author{
Abdul Rahiman Zubair Kotikulam and Shanavas Moosafintavida*
}

Azteca University, Mexico, North America

*Corresponding author: dr.shanavas@univ-azteca.com

Received: 19-01-2020

Revised: $14-04-2020$

Accepted: 24-05-2020

\begin{abstract}
Virtual currencies, a modern frame of private cash, has been well-cited and well-discussed within the close past. The support for virtual currency was bestowed due to the loss of trust in the banking sector, the fear of loss of capital, volatile low-interest rates, and the weakness of existing currencies. The expansion of virtual currencies (VCs) have been taken after not just by the media and industry experts all over the world - there seldom may be found an individual who has not ever listened the term 'bitcoin'. However, the rise of virtual currencies esteem on the market and the developing ubiquity around the world open several challenges and concerns for trade and industrial economics. As the money flow of virtual currencies are monitored only online by the secret group of volunteers (also known as peer), each transaction is verified and well documented. Currently, there are approximately 10,000 businesses worldwide recognize and accept the virtual currencies payment, and the number is escalating progressively. This article analyses the gains and impediments of virtual currencies in contrast to existing tangible currencies and offers an outlook to a contemporary banking framework with high Comprehensibility and the chance to lead a paradigm shift in the world of exchanges and banking. The challenge of feasible guidelines of the impending growth of $\mathrm{VCs}$ is raised due to the rising number of VCs along with improvising on the legal framework of VCs. The rise and drop of VC's, in terms of its unique aspiration, serves as a cautionary story within the advanced age - it uncovers how bright developments that might challenge control and the consolidation of capital gotten to be co-opted and colonised by capital. At long last, the article offers a dialogue of the conceivable dynamic uses of the digital innovation virtual Currency has facilitated.
\end{abstract}

Keywords: Virtual Currencies, Outlook, Future, Digital, Economy 
Bitcoin, the primary private decentralised digital currency with a global reach, has more than 1,500 competitors in the virtual currency (VCs) world. Bitcoin remains the leader among other VC's as only a few records significant advertise turnover and capitalisation since introduced in 2008. Bitcoin has been broadly championed in a few quarters as being free of any third-party control such as government or a central bank. As Bitcoin and other VCs were generally examined and propagated by IT specialists, they were considered a specialty phenomenon - a sort of technological folklore - that might vanish any day. Therefore, a little attention was given to Bitcoin and other VCs initially from economists or monetary and regulatory authorities. The circumstance has changed drastically since Bitcoin did not disappear and, on the opposite, has proceeded its extension and found followers world- wide, it has ended up a prevalent subject of dialogue among financial analysts, financial market specialists, and indeed politicians.

Considering the financial control of the Internet, steady development must be considered. The total around the world e-commerce turnover was around 1.248 billion US dollars in 2013. A multiplying of this turnover is anticipated for the coming years[1]. In arrange these figures accurately, they amount to as much as the combined turnover of the three world-leading companies Illustrious Dutch Shell, ExxonMobil, and Walmart per year [2]. The Internet stands for "always-on", acquiring 24/7, speedy bargains, individual responsibility, constrained control by specialists and a high degree of secrecy [3]. These characteristics have moreover been combined with the unused marvel which happened for the primary time in 2009 - "virtual currencies" (VC; in some cases, too called "cryptocurrencies"). VCs suggests math-based peer-to-peer digital currencies that have no central administrating specialist and no central observing or oversight [4]. Right now, there are more than 270 distinctive VCs in utilize, and the number is expanding consistently. bitcoin is the most unmistakable one [5]; others incorporate Litecoin or Swell [6].

Virtual currency Transactions started developing but somewhat at low level. At the meantime, the number of transactions daily was assessed at 100,000 in comparison to around 295 billion exchanges within the classic banking procedure [7]. This article investigates the wonder of VCs and their potential effect on both financial markets and monetary policy, as well as on the gathered central bank monopoly on issuing cash. It also consider to start with an outline of the financial and mechanical characteristics of the VCs phenomenon and will at that point give a brief history of VCs, an investigation of their focal points and impediments, and an audit of the administrative approaches to VCs in different jurisdiction. The subject of this article is insulant examined in Asian regions and makes the necessity to investigate the concept, sort, lawful direction, and development possibilities of VCs, based on the examination of extraordinary writing and scientific publications of Asian and remote analysts.

The objective of the research is to investigate the concept of VCs within the modern economy. The following investigate tasks have been set to realize the point of the research:

* To investigate the concepts of a computerized and virtual economy and currencies

* To systematize VC scientific categorization, to create a VCs classification, and provide its characterization

* To depict the legitimate system of VCs and give an assessment of improvement openings for VCs

* To draw conclusion.

Another zone of study explores how digital monetary forms can impact the way money related policy is conducted. But none of this work can be connected to virtual Currencies that are based on a block-chain and work without an assigned third-party to issue the cash [8]. Advocate here that the appropriation of 
digital monetary standards can encourage the execution of a negative interest rate policy, whereas [9] proposes that staging out paper currency can undercut undesirable charge avoidance and criminal exercises. Our discoveries complement this work as we establish some potential bounds on the costs that can be exacted on individuals through central bank-issued digital currency. At last, [10] show cryptocurrencies as privately issued fiat monetary forms and analyse - within the convention of the writing on the free banking era - whether competition among diverse monetary standards can accomplish cost soundness and productivity of exchange.

The Trust in a VC's framework includes the exchange of three thoughts: the security of the blockchain, the health of the mining biological system and the value of the digital currency. Adequate mining exercises are required for guaranteeing the security of the block-chain, safeguarding it against assaults and untrustworthy practices. Besides, as it were when users believe the security of the framework will the VCs be universally acknowledged and exchanged at a high value. Finally, the value of the digital currency boosts the reimburse strategy to incentivize diggers to lock in in costly mining activities.

\section{Theoretical Framework of Virtual Currency}

The field of Virtual currency is exceptionally young, with the primary publications as it was showing up within the early 2000s, generally based on theoretical models. These models appeared a potential way to form an inventive $\mathrm{VCs}$, but they did not analyse concrete parameters due to a need of existing models and monetary standards [11], [12]. An invention was born in 2008 with the publication of Satoshi Nakamoto around "bitcoin", when it was declared they would be introduced to the markets in 2009 [13].At the same time, [14] distinguished some of the challenges for Virtual currencies: security risk, the danger of virtual money framework collapse, impacts of real-world financial frameworks,money laundering, tax evasion and online criminal and value fluctuation of virtual cash. These distinguished challenges are the premise for most of the afterward created articles and will be the foundation for the discourse of points of interest and disadvantages in this article as well. After a year of launch, many shrewd articles have opened their viewing point undeniably. Earlier, it was more the thought and the vision of VCs, so by and by taken after uncommonly specific and truly discernment of VCs in different logical headings, such as the extension of $\mathrm{VC}$ for companies as a steadfastness instrument [15], security controls [16], profitdriven manhandle [17], by and expansive control [18], progression inside the budgetary trade world [19], the authentic status [20], challenges inside the assess evaluation and exchange rates [21]. The number of articles has been reliably creating, showing up the extended level of thought on Virtual Currencies. Moreover, there is no reliable and commonly agreed-upon definition of what a Virtual currency is, primarily due to these diverse scientific fields which have their distinctive points. Other than the field of development, IT (specialized prerequisites), law (treatment of this peer-to-peer money) and economy (cash, costs, instability) are touched upon, which makes it more complex.

Underneath, an outline of the most-cited definitions of VC is given as well as two depictions of a concrete example (bitcoin) to form it more substantial.

In 2008, Nakamoto [13] initially defined Bitcoins as "bitcoin is a digital, decentralized, partially anonymous currency, not backed by any government or other legal entity, and not redeemable for gold or other commodity. It relies on peer-to-peer networking and cryptography to maintain its integrity." 
* In 2012, European Central Bank [7] well-defined VCs as "A virtual currency is a type of unregulated, digital money, which is issued and usually controlled by its developers, and used and accepted among the members of a specific virtual community."

* In 2013, GAO [23] gave a definition to VCs as "There are no legal definitions for a virtual currency. A virtual currency is, generally, a digital unit of exchange that is not backed by a governmentissued legal tender."

* In 2014, Ateniese [22] defined bitcoin as "bitcoin is a peer-to-peer (p2p) electronic cash system that uses a distributed time stamp service to record transactions in a public ledger (called the Blockchain). A critical component of bitcoin's success is the decentralized nature of its architecture, which does not require or even support the establishment of trusted authorities."

In 2018, Directive of the European Parliament [27] defines the term "virtual currencies" as "a digital representation of value that is not issued or guaranteed by a central bank or a public authority, is not necessarily attached to a legally established currency and does not possess a legal status of currency or money, but is accepted by natural or legal persons as a means of exchange and which can be transferred, stored and traded electronically".

There is a settled supply of 21 million bitcoin and no money related or governmental authority has the right to create bitcoin. As it were the coordinates peer gather, so-called "miners", make bitcoin and have the duty for the currency and the exchanges. The mineworkers control every single exchange through an open record framework, known as the block-chain, that approves every single exchange [24]. In comparison to genuine monetary forms (e.g. US dollar or euro), the control figure is given by the peer gather, good for nothing central introduction and lower exchange costs. The following segment deals with different kinds of VCs and builds the premise for the upcoming discussion of the benefits and shortcomings of VCs. Three different sorts of VCs are known and recognized based on the perception of the European Central Bank [7] and are talked about by scientists:

Closed Virtual Currency Policies: Virtual currencies have been called "closed" or "fictional cash" when they have no official association to the genuine economy, for illustration, currencies in enormously multiplayer online role-playing diversions such as World of Warcraft. Whereas there may be a dark advertise for trading such monetary standards or other virtual resources for real-world resources, this can be as a rule forbidden by the games' terms of service. This kind of currency has no connect to the "real" world and is for the most part utilized in online diversions [25]. Virtual cash is earned exclusively by online execution. This kind is additionally called "in-world money" [14] since it measures in-world utilization, in-world generation, in-world speculations, in-world services, and indeed in-world virtual government investing. No trade or buys exterior the virtual community (e.g. one amusement) is conceivable. An exchange between two distinctive virtual worlds (e.g. two different games) is not conceivable; the result is "nontransferability" [14]. Offering or utilizing the online currency within the genuine world is entirely illegal. A prior, concrete illustration of a closed framework in online diversions are the gold coins of Ultima Online [26].

* Virtual Currency Systems with Unidirectional Movement: VC can be obtained with "real money" (e.g. dollar, euro, yen) at a trade rate. A back-to-back exchange is not conceivable. Illustrations of buys are investing in virtual merchandise or administrations once more, but now 
and then real goods and genuine administrations can be acquired as well [7]. The video gaming company Nintendo presented so-called Nintendo Focuses. Clients might purchase these focuses on credit card instalments or by purchasing Nintendo cards in retail stores (comparable with prepaid cell phone cards or Apple iTunes vouchers). The Nintendo focuses may be utilized online and offline: online in a few recreations for superior gear or levels, offline for acquiring merchandise in Nintendo stores. Encourage cases are the previous Facebook Credits (presently discontinued credits to purchase virtual merchandise and administrations within Facebook), Amazon Coins (which Arouse clients can trade real money for and after that utilize to purchase applications), or frequent-flyer focuses like Miles and More from Lufthansa, Project Entropia Dollars or Q Coins [4]. The commerce issuing the coupon capacities as a central specialist remained unaltered for 100 a long time until modern innovation empowering credit cards got to be more common within the 1980s, and credit card rewards were designed. The most recent incarnation drives the increment of web commerce, online administrations, the advancement of online communities and diversions. Here virtual or diversion currency can be bought, but not traded back into genuine cash [28].

- Virtual Currency Plans with Bidirectional Flow:A virtual currency that can be bought with and sold back for legitimate delicate is called convertible money. It can be decentralized, as for example bitcoin. Therefore, users can purchase, offer, or trade virtual cash, continuously related to the trade rate. In this manner, the VCs are comparable with any other genuine currency and can be utilized for buys online and offline [7]. In 2011, the American company SEE Virtual Universes bought a virtual planet called "Calypso" in an MMO online amusement for six million US dollars. The MMO was set up in 2003 and has more than 950,000 clients [29].

\section{Legal Framework of Virtual Currency}

Despite the developing attractiveness of virtual currency, a few countries have illustrated their negative demeanour. On social systems (Twitter, Facebook and Google), it is illegal to put advertisements for VCs, thus protecting shoppers from a high budgetary hazard. In China, deals with VCs are totally illegal since 2018, the Vietnamese government has too prohibited them, as well Indonesia has pronounced the VCs to be unlawful implies of instalment. Bitcoin values have been negatively influenced by South Korean hypotheses over bans on exchanging in VCs. The European Union (EU) and the United States of America (USA) have not prohibited exchanging in the virtual Currencies, although they concur on the presentation of a fitting administrative system. Though a few nations have prohibited virtual currencies, some countries have seen their potential. Hence, the Central Bank of Singapore tests its own VCs, the Swedish Central Bank is examining the presentation of crypto Krona, but Switzerland has made the foremost positive environment for improvement of VCs. In Estonia, the Mothership venture is implemented - the trade of VCs and connecting it with e-residency [30]. Studies on the legal framework of VCs within the EU nations [31], Japan, Germany, the USA, and Russia, the USA, Switzerland, and the People's Republic of China [32] appears that the lawful system for VCs is at the early stage of advancement.

In view of the changing regulations of virtual currencies, another issue is that it may shift from nation to nation whether the ownership or exchange in virtual currencies is lawful. In expansion, there is the issue of undesirable, non-transaction-related content - so-called non-financial arbitrary data - within the block-chain. This content is embedded through the commentary work of the block-chain for transactionrelated data. By mishandling this component unlawful or at slightest questionable substance (e.g., child 
obscenity, politically touchy substance, copyright encroachments) is entered into the block-chain. Due to the permanence of the block-chain, it cannot be removed reflectively and hence can illegalise a whole block-chain framework. As of now, the ownership of the block-chain would at that point be sanctionable by law. More up to date eras of the block-chain will execute suitable security instruments by default as a safeguard; more seasoned forms can as it were, but barely, drop back on the chameleon hash or forking.

In terms of money laundering or terrorist financing, there is, opposite to open conclusion, no more noteworthy chance than with routine monetary forms, indeed in spite of the fact that abuse, as a matter of fact, was a big issue within the early days of Bitcoin \& Co. It is still a common misinterpretation that Bitcoins are mysterious when, at best, they are pseudonymous. But other virtual monetary standards highlighting indeed more secure 'anonymity protocols', such as Monero, are traceable by way of back and likelihood calculation and by cross-referencing extra exchange information. Other than, the IP address of a computer can be logged, and indeed blending administrations utilized to conceal the beginning of virtual currencies have their impediments. A study by the National College of Singapore set up that law requirement is often effective in following back virtual cash exchanges in 88 to 98 per cent of cases -a higher rate than with paper money.

Other than, those most powerless to the disasters of virtual currencies are, as regular, customers. This is often especially important given that, in common, no customer assurance rules apply to virtual monetary forms, meaning that stores of virtual monetary standards are not ensured by bank store protections [31]. Moreover, there are no frameworks or components required by law to secure those resources from robbery or hacking. Still, the chance of being hacked is not limited exclusively to virtual currencies and their stages. Banks have been targets for a few times, and most as of late in Taiwan, Ecuador, Ukraine, and the Bangladesh central bank in 2017 [32]. With the expanding number of VCs, with the fortifying of the legal regulation of VCs, the issue of the conceivable headings of encourage development of VCs emerges. Dissecting the effect of VC on money related approach, contend that the most address is whether they have the potential to compete with the imperial monetary forms issued by central banks [32]. That is, the money related dominance of major central banks and major currencies seems to stay unchallenged within the close future. However, youthful, and technically sophisticated individuals frequently welcome the conceivable outcomes advertised by the block-chain and decentralized virtual monetary forms. As normal although, developments - particularly of this potential greatness - are met with distrust and indeed fear. It remains to be seen how long it will take for the block-chain and the advances it supports to eventually persuade individuals of its inborn potential and future sustainability.

\section{Future Outlooks of Virtual Currency}

As for long term utilize of bitcoin, the best-known VCs, two points of see rule: long-run cash or the instalment framework, for instance, savvy contracts. VCs guarantee shrewd contracts. These are advanced contracts between two parties who do not know each other or do not believe the other party, and they permit secure and mysterious commerce or stock trade exchanges without obstructions of the mediators - central teach law or administrative frameworks. Keen contracts work the same way as conventional ones - they characterize the rules and punishments for executing or breaking the contract, but, not at all like the case of the paper-based contracts, everything is done consequently. Decentralization is the key to a safer and more troublesome to break framework [33].

A few of the impediments that VCs directly confront - such as the reality that one's digital fortune 
can be deleted by a computer crash, or that a virtual vault may be stripped by a programmer - may be overcome in time through mechanical progress. What will be harder to overcome is the essential paradox that bothers VCs - the more prevalent they ended up, the more direction and government investigation they are likely to draw in, which dissolves the basic preface for their presence. The number of vendors who acknowledge VCs has relentlessly expanded; they are still exceptionally much within the minority. For VCs to get to be more widely utilized, they got to begin with pick up far-reaching acknowledgement among shoppers. In any case, their relative complexity compared to customary monetary standards will likely discourage most individuals, but for the technologically proficient.

A VCs that tries to end up a portion of the standard money related framework may need to fulfil broadly unique criteria. It would have to be mathematically complex (to avoid fraud and hacker attacks) but simple for customers to get it; decentralized but with satisfactory customer shields and security; and protect client namelessness without being a conduit for tax avoidance, money laundering and other evil exercises. Since these are impressive criteria to fulfil, is it conceivable that the foremost popular VCs in some years' time might have traits that drop in between heavily regulated fiat monetary forms and today's VCs? Whereas that possibility looks farther, there's small question that as the driving VCs at the show, Bitcoin's victory (or need thereof) in dealing with the challenges it faces may decide the fortunes of other VCs within the long-time ahead.

\section{Pros and Cons of Virtual Currencies}

In common, all businesses can utilize VCs comparable with electronic payment services like credit card systems (e.g. VISA, Mastercard) or cash exchanges. There are no official confinements, limitations or regulations known [34]. By presently, around 10,000 businesses around the world acknowledge instalments with VCs. This number is expanding relentlessly since it is exceptionally simple to take an interest. Proficient add-ins for companies' websites are available to grow the instalment choices for clients without tall endeavours and costs; it is comparable to adding Google maps to the site or the alternative to pay by credit card [35].

\section{Pros of VCs}

* World-Wide Toll-Free Exchanges: Within the setup banking world, person exchanges from "A" to " $\mathrm{B}$ " are often associated with expenses, depending on the complexity and the internationality. Level rate or individual feeds are separated between. Exchanges are toll-free and particularly curiously for remote exchanges [36].

* No Possibility of Censorship or Blocking: This perspective is particularly curiously for ranges with political or financial turbulences [37]. Within the greatly close past, the European Union has solidified numerous accounts of Russian citizens and indeed Russian companies due to the seen mischief of President Putin in a political strife with the Ukraine [38].

* No Inflation: Due to the fixed number of bitcoins, a cheapening of the currency cannot happen in terms of the classical multi-production of money. Typically based on the arranged number of 21 million bitcoin which frame the premise of the system. As it were supply and request impact the esteem of bitcoin [39]. 
* Exchange Time: Several researchers may discover choices to secure a quick exchange time. Changes within the prepare make it possible to utilize $\mathrm{VC}$ indeed at fast-food eateries [40] or nibble machines [16]. This can be characteristic of the another organizes within the creating handle of $\mathrm{VC}$ and ought to be coordinated in the common exchange process.

- Openness/Alter Resistant: The framework is at first simple to get it in differentiate to the realworld hone of money creation. There are a setup number of bitcoin accessible; the esteem is based on supply and request and so responds with fluctuations in esteem. All data is known, making it straightforward. Moreover, extortion with fake cash is prohibited, but this needs to be analysed in more detail within the future [41].

* Sustainability: One exceptionally "hot" current trend within the financial framework comprises of the aspiration to take after an item from the end- to-end. This suggests knowing where the person components have their beginning and whether they are morally and morally on a worthy level within the fabricating segment. This requires a parcel of effort for the companies [42]. Within the case of virtual money, this traceability is given but beneath the cloak of anonymity.

\section{Cons of VCs}

* Acceptance/Trust: The most challenge for innovation in common may be a need for acknowledgement within the broad public. Users of VCs are regularly considered to be "IT hackers". The need of acknowledgement by governments, banks or the economy is for the most part based on the fear of losing control and with the misfortune of control the misfortune of money and the commerce show [43]. Wander capital is given to start-ups working within the field of VCs, e.g. the previous Facebook author and the Winklevoss twins contributed a huge sum [18]. Wander capital stands in for challenges, for risk-taking and for innovativeness, but on the other hand for openings, making inventive arrangements and openness.

Money Laundering, Tax Dodgingand Cyber Offender: VCs are made by either virtual money creation rules or through mining [44]. The danger of intercession by programmers exists; they may create cash for themselves or alter the sum of their credit. The validity, particularly in terms of flawlessness and rightness, is not given in its aggregate [45]. Illicit get to existing accounts of VC is extensively reported. The foremost fabulous case was in 2014, where programmers utilized a gap within the security framework to alter exchanges between the peers; roughly 100 cases are known with abnormalities at different computerized stock trades [46]. The banking program "Know your customer", which needs genuine characters and homes of account holders, gets an indeed higher need [47]. Tax avoidance is more pertinent due to a need for directions, laws, and control frameworks. Arbitrage profit through trade rate vacillations can be considered as a partitioned trade show due to the amazingly tall instability. Taxes for these picks up are right now not executed since most governments have not recognized this hole, however, and no laws are on the way however either.

Limited Group of Users: The constrained group of users makes it suspicious in totally different ways. The trade model is created to pick up wealth for the founder, within the case of bitcoin a group of obscure people. bitcoin is currently used by around 130,000 clients, and as it were a little bunch features a higher number of bitcoin and the exchanges are constrained so far [48]. 
There is a chance of the discretion of the originators, comparable with the virtual cash within the online amusement World of Warcraft, where users may purchase virtual genuine domain for genuine money and be dispossessed by the founders. Due to the restriction of central specialists, there was no store ensure [49].

* Changing Values of Virtual Money: Value variance is a self-evident challenge of virtual money due to the constrained utilize of exchanges (around 100,000 exchanges with VC are completed each day in comparison to 295 billion with genuine cash). The ordinary challenge of supply and request of monetary forms is additionally known by less important currencies (e.g. Brazilian Real or Turkish Lira) within the genuine world, but it isn't comparable with the euro or the Swiss franc or indeed gold [50].

* Collisions of Practical Financial Systems: Autonomous money not controlled by states or groups of states leads to vulnerability, although it is a development. The coordinate gets to and conceivable direction of the most elevated occurrences falls absent, and the unused central occasion is the peer-to-peer collective. This implies the control of banks and governments may well be constrained within the future [51]. Right presently, the effect of VC within the world exchange is little but relentlessly developing. It is accepted that VC is an expansion of the existing instalment choices such as cash, credit cards or the trade of administrations. Due to the rising significance of digitalization, the rate of exchanges is anticipated to be emphatically increasing.

* The Threat of Virtual Money Framework Collapse: The danger of a collapse of VC and their exchange is justified and was confirmed lately in spring 2014 with the end of the until then most known and most used exchange point Mt. Gox, which was marked by irregularities and inaccuracies [47]. More than $60 \%$ of the bitcoin trading volume was provided by Mt. Gox before they stopped the exchange of bitcoin and then took their website offline and filed for insolvency. The consequences were serious; allegedly more than 800,000 bitcoins were lost to hackers. This theory is strongly challenged by various scientists, who have determined that only about 400 bitcoins affected by the hacker attack may be lost [52]. So, Mt Gox appears in an even worse light as the former main trading centre and has damaged the confidence in bitcoin in the long term.

\section{CONCLUSION}

Virtual currencies are a modern shape of private cash, which was generally truant from economic life within the $20^{\text {th }}$ century. Much appreciated to utilizing Block-chain innovation, the exchange systems of VCs are generally secure, straightforward, and quick. Not at all like their $18^{\text {th }}$ and $19^{\text {th }}$-century paper predecessors, VCs are utilized globally, ignoring national borders. The distinction between digital currencies and VCs can be caught on in a similar mould: where digital currencies are a non-physical representation of conventional fiat money, VCs speak to a genuine online resource that does not has value other than in its virtual world. VC could be a type of computerized currency, but the opposite explanation is not genuine. In this way, all VCs are advanced, but not all digital currencies are virtual.

This article acknowledges the imperative position within the logical field and underlines the existing premise for a novel, important development within the financial administration's segment. Straightforwardness and traceability of cash flows and in this way, maintainability are central topics. The broad certainty in banks is harmed, so there's sufficient space for unused, utilitarian money. Hence, the creators of this 
article foresee $\mathrm{VC}$ to be a victory story that might be gotten to be comparable to credit card entrance around the world. The preferences of $\mathrm{VC}$ are concrete and unquestionable. The drawbacks are generally delicate realities like a need of belief, need of acknowledgement, or a common fear of the modern, fear of a collapse of the existing system.

The acceptance and the confidence in this modern currency might increment promptly with an official, central authority within the lead. It might be a recently made World Bank with all rights and obligations, the alter to be controlled by the peer-to-peer group, but with the security of no inconsistencies and mistakes. Considering the impediments of this work, the youngest of the field and the need for encounters ought to be expressed. The existing writing is spread over distinctive areas of science, so as it were a limited number of works exist and these are in some cases not comparable because of distinctive backgrounds. This article is one of the primaries in which points of interest and impediments are recorded in a scientific way, utilizing current sources from the scholastic world as well as from other sources. The diagram of advantages and drawbacks can serve as a, to begin with, step to conveying a more point by point picture of the field within the future.

The financial dominance of major central banks and major monetary standards seems to stay unchallenged within the close future. In any case, the prospects may see different in littler money related wards, particularly in nations where the sovereign currency remains inconvertible or does not appreciate the belief of financial operators due to its poor record of solidness or due to political and financial vulnerability. Such nations already struggle with the phenomenon of money substitution within the frame of spontaneous dollarization or euroization. Therefore, one cannot run the show out that future advancement within the region of information technologies can bring indeed more straightforward, secure, and less demanding to utilize variations of VCs. This might increase the chances for VCs to viably compete with imperial monetary forms, counting the major ones.

Future investigate ought to be embraced in a convenient way to get it the phenomenon better. Empirical work is essential to get it the focuses of see of companies and end-users better and to get it what the real points of interest and impediments are within the eyes of potential users. Curiously may too be the examination of influencing variables, needs and relationships between objective information and values of companies utilizing VC. Another curiously inquire about address would be the empirical study of extortion per exchange and comparing the trend of bitcoin on stock markets in comparison to real-world currencies just like the US dollar or the euro. An unused period of exchanges and banking has as of now begun. The straightforwardness of virtual monetary forms will change the commerce world dramatically.

\section{REFERENCES}

1. Statista. 2014b. E-Commerce-Umsatz in Deutschland 1999 bis 2013 und Prognose für 2014 (in Milliarden Euro). Retrieved 30.08.2014, from http://de.statista.com/statistik/daten/studie/3979/umfrage/ecommerce-umsatz-in-eutschland-seit-1999/

2. Fortune. 2014. Fortune 500 2014. Retrieved 30.08.-2014, from http://fortune.com/fortune500/GAO, United States Government Accountability Office. (2013). Virtual economies and currencies Additional IRS Guidance Could Reduce Tax Compliance Risks.

3. Rennhard, M. and Plattner, B. 2002. MorphMix: Peer-to-Peer based Anonymous Internet Usage with Collusion Detection. Paper presented at the Privacy in the Electronic Society 
4. FATF Report. 2014. Virtual Currencies Key Definitions and Potential AML/CFT Risks. Paris: Financial ActionTask Force on Money Laundering / OECD.

5. Turpin, J.B. 2014. Bitcoin: The Economic Case for a Global, Virtual Currency Operating in an Unexplored Legal Framework. Indiana Journal of Global Legal Studies, 21(1): 335-368.

6. Middlebrook, S.T. and Hughes, S.J. 2014. Regulating Cryptocurrencies in the United States: Current Issues and Future Directions. Wm. Mitchell Law Review, 40: 813-1158.

7. European Central Bank. 2012. Virtual Currencies Schemes.

8. Agarwal, R. and Kimball, M. 2015. "Breaking through the Zero Lower Bound. "Working PaperWP/15/224, International Monetary Fund.

9. Rogoff, K.S. 2016. The Curse of Cash, Princeton University Press.

10. Fernandez-Villaverde, J. and Sanches, D. 2016. “Can currency competition work?”, NBER Working Paper 22157, National Bureau of Economic Research.

11. Buttyan, L. and Hubaux, J.P. 2001. Nuglets: a virtual currency to stimulate cooperation in self-organized mobile ad hoc networks.

12. Irwin, D., Chase, J., Grit, L. and Yumerefendi, A. 2005. Self-recharging virtual currency. Paper presented at the ACM SIGCOMM workshop on Economics of peer-to-peer systems.

13. Nakamoto, S. 2008. Bitcoin: A peer-to-peer electronic cash system. Consulted, 1(2012), 28.

14. Guo, J. and Chow, A. 2008. Virtual money systems: a phenomenal analysis. Paper presented at the $10^{\text {th }}$ IEEE Conference.

15. Buchinger, U., Ranaivoson, H. and Ballon, P. 2013. From Loyalty Points to Virtual Currencies: Expanding LoyaltySchemes for Mobile Platforms. Paper presented at the International Conference on Mobile Business Paper 9.

16. Bamert, T., Decker, C., Elsen, L., Wattenhofer, R. and Welten, S. 2013. Have a snack, pay with bitcoins. Paper presented at the 2013 IEEE Thirteenth International Conference.

17. Huang, D.Y. 2013. Profit-driven abuses of virtual currencies.

18. Ly, M.K.M. 2014. Coining Bitcoin's" Legal-Bits": Examining the Regulatory Framework for Bitcoin and Virtual Currencies. Harv. J. Law \& Tec., 27(587-587).

19. Villasenor, J., Monk, C. and Bronk, C. 2011. Shadowy Figures: Tracking Illicit Financial Transactions in the Murky World of Digital Currencies, Peer-to-peer Networks, and Mobile Device Payments.: Brookings Institution.

20. Bollen, R. 2013. The Legal Status of Online Currencies: Are Bitcoins the Future? Journal of Banking and Finance Law and Practice, pp. 1-38.

21. Guo, J. and Xie, M. 2013. Achieving Satisfied Virtual Exchange Rates through Multiple-Stage Virtual Money Supply. Paper presented at the International Conference on In Cyberworlds. 
22. Ateniese, G., Faonio, A., Magri, B. and de Medeiros, B. 2014. Certified bitcoins. Paper presented at the Applied Cryptography and Network Security.

23. GAO, United States Government Accountability Office. 2013. Virtual economies and currencies Additional IRSGuidance Could Reduce Tax Compliance Risks.

24. Deloitte. 2014. The new gold rushes.

25. KPMG. 2013. Virtually Unregulated Countering Virtual Currency, Money Laundering in the $21^{\text {st }}$ Century: KPMG.

26. Dibbel, Julian. 2006. Play Money: Or How I Quit My Day Job and Made Millions Trading Virtual Loot: Perseus Books.

27. Directive (EU) 2018/843 of the European Parliament and of the Council of 30 May 2018 amending Directive (EU) 2015/849 on the prevention of the use of the financial system for the purposes of money laundering or terrorist financing, and amending Directives 2009/138/EC and 2013/36/EU (Text with EEA relevance), OJ L, 2018-06-19, retrieved 2019-09-18.

28. Kanner, Bernice. 1992. New York Magazine, pp. 18.

29. Buffed.de. 2014. Guinness Weltrekord: Teuerster Kauf eines virtuellen Besitztums für 6 Millionen USDollar. Retrieved 31.08.2014, from http://www.buffed.de/Planet-Michael-PC-235950/News/GuinnessWeltrekord-Teuerster-Kauf-eines-virtuellen-Besitztums-fuer-6-Millionen-US-Dollar-819238/

30. Rupeika-Apoga, R. 2018. Kriptovalūta- vieni aizliedz, citi mēǵina pieradināt. Dienas Bizness, 10.04.2018.

31. European Central Bank. 2015. Virtual currency schemes - a further analysis. Retrieved July 27, 2018, from https://ej.uz/v7cw

32. Dabrowski, M., Janikowski, L. 2018. Virtual currencies and central banks monetary policy: challenges ahea. Retrieved July 27, 2018, from https://ej.uz/gbe9

33. Buimistere, A. 2018. Nost ar bankām (un riska kapitālistiem)! Forbes, 2018.gada marts, Nr.80. Retrieved July 27, 2018, from https://nodepower.io/forbes.pdf

34. PWC. 2014. Virtual currencies: Out of the deep web, into the light. In r. Issues, and opportunities around the digitization of money (Ed.)

35. Handelsbaltt. 2014. Zahlen wir bei Ebay bald mit digitalem Geld? 31.08.2014, from http://www. handelsblatt.com/unternehmen/it-medien/einfuehrung-von-bitcoins-zahlen-wir-bei-ebay-bald-mitdigitalem-geld/10338526.html

36. Reid, F. and Harrigan, M. 2013. An analysis of anonymity in the bitcoin system. In Y. Altshuler, Y. Elovici, A. B.Cremers, N. Aharony \& A. Pentland (Eds.), Security and Privacy in Social Networks (pp. 197-223): Springer New York.

37. Brezo, F.G. and Bringas, P. 2012. Issues and Risks Associated with Cryptocurrencies such as Bitcoin. Paper presented at the International Conference on Social Eco-Informatics.

38. The Wall Street Journal. 2014. Berlin Lays Groundwork with German Public for Stiffer Russian Sanctions. Retrieved 31.08.2014, from http://online.wsj.com/articles/berlin-lays-groundwork-withgerman-public-for-stiffer-russian-sanctions-1406482633 
39. Meiklejohn, S., Pomarole, M., Jordan, G., Levchenko, K., McCoy, D., Voelker, G.M. and Savage, S. (2013). Afistful of bitcoins: characterizing payments among men with no names. Paper presented at the 2013 conference on Internet measurement conference.

40. Karame, G., Androulaki, E. and Capkun, S. 2012. Two Bitcoins at the Price of One? Double-Spending Attacks on Fast Payments in Bitcoin. IACR Cryptology e-Print Archive, pp. 1-17.

41. Barber, S., Boyen, X., Shi, E. and Uzun, E. 2012. Bitter to better-how to make bitcoin a better currency Financial Cryptography and Data Security (pp. 399-414): Springer Berlin Heidelberg.

42. Closs, D.J., Speier, C. and Meacham, N. 2011. Sustainability to support end-to-end value chains: the role of supply-chain management. Journal of the Academy of Marketing Science, 39(1): 101-116.

43. Darlington III, J.K. 2014. The Future of Bitcoin: Mapping the Global Adoption of World's Largest Cryptocurrency Through Benefit Analysis. University of Tennessee, Knoxville.

44. Guo, J. and Gong, Z. 2011. Measuring virtual wealth in virtual worlds. Information Technology and Management, 12(2): 121-135.

45. Hanley, B.P. 2013. The False Premises and Promises of Bitcoin. arXiv preprint arXiv:1312.2048, pp. 1-32.

46. eRecht24. 2014. IT Sicherheit: Internetkriminalität - Hacker legen virtuelle Wägung Bitcoin lahm. Retrieved01.09.2014, from http://www.e-recht24.de/news/it-sicherheit/7833-internetkriminalitaethacker-legen-virtuelle-waehrung-bitcoin-lahm.html],http:/www.taz.de/!134242/

47. Barnett, E.R. 2014. Virtual Currencies: Safe for Business and Consumers or just for Criminals? Paper presented at the $13^{\text {th }}$ European Security Conference \& Exhibition.

48. Statista. 2014a. Anzahl der My Wallet-Benutzer in den Monaten November 2012 bis Juni 2014 (in 1.000). Retrieved 01.09.2014, fromhttp://de.statista.com/statistik/daten/studie/283307/umfrage/anzahlder-my-wallet-benutzer/

49. Andrychowicz, M., Dziembowski, S., Malinoswki, D. and Mazurek, L. 2013. Fair Two-Party Computations via Bitcoin Deposits? IACR Cryptology e-Print Archive, pp. 837.

50. Yermack, D. 2013. Is Bitcoin a Real Currency? National Bureau of Economic Research, (No. w19747).

51. Stiller, B., Schmitt, C., Garg, R., Bocek, T., Dönni, D. and Machado, G. 2014. Internet Economics VIII. In T. R. N.IFI-2014.01 (Ed.): University of Zurich - Department of Informatics (IFI).

52. Heisse.de. 2014. Studie stellt Verlust bei Mt. Gox in Zweifel. Retrieved 01.09.2014, from ttp://www. heise.de/newsticker/meldung/Studie-stellt-Bitcoin-Verlust-bei-Mt-Gox-in-Zweifel-2156255.html 
